\title{
Entertainment Design - A Module in Expectation Management
}

\author{
D Galloway \\ University of Abertay Dundee \\ School of Computing \& Creative \\ Technologies \\ Kydd Building, Dundee DD1 1HG \\ +44(0)1382 308693 \\ d.galloway@abertay.ac.uk
}

\author{
Dr I Donald \\ University of Abertay Dundee \\ Digital Innovation Studio Manager \\ White Space \\ Kydd Building, Dundee DD1 $1 \mathrm{HG}$ \\ +44 (0)1382 308693 \\ i.donald@abertay.ac.uk
}

\author{
Dr E Dempster \\ University of Abertay Dundee \\ School of Computing \& Creative \\ Technologies \\ Kydd Building, Dundee DD1 1HG \\ +44(0)1382 308229 \\ e.dempster@abertay.ac.uk
}

\begin{abstract}
Entertainment Design is an undergraduate module which aims to provide the student with an understanding and awareness of the processes involved in designing and developing a piece of interactive entertainment. At first glance this may appear to be a straight forward task for a broadly experienced academic. However, everything becomes far more complex when shared teaching, students from three different degree programmes, selfdirected group work, and mentors from industry are thrown into the mix. In this paper, we analyse and discuss the development of the module, the creative and collaborative processes that have formed the core of its delivery, and the mutually rewarding outcomes and opportunities that arise when the expectations of all those involved are managed appropriately.
\end{abstract}

\section{INTRODUCTION}

Since being established in 2005, Entertainment Design has constantly evolved in response to and in anticipation of the various challenges, requirements and of opportunities of higher education. In its previous form, under the title of Game Design, the module focussed heavily on paper-based coursework and examination, to measure the student's ability to contextualise their ideas and concepts in terms of established game development principles. Whilst this had academic relevance, feedback from students and industry partners suggested that a more hands-on, collaborative approach would be more appropriate. Structural changes to the teaching team brought new expertise and skills, and provided the opportunity for the module to be re-designed and submitted for approval.

The revised module runs for 24 weeks and is split over two academic semesters, with semester one focussing on individual project work to encourage the development of ideas and the generation of concepts. Following on from this, semester two chiefly involves collaborative work in small teams to take a concept from an initial idea to an engaging prototype. The change to the module title from Game Design to Entertainment Design and their respective aims was to broaden the scope for the student's ideas, as previous output tended to be variations on standard two-dimensional platform games. However, students are now encouraged to innovate and conceptualise engaging interactive forms - such as viral marketing, alternate reality games and interactive narratives. To assist the students in developing these forms, they have access to a range of industry standard equipment and resources, including green-screen studio space, high-definition cameras, and a fully equipped audio recording and performance suite.
The learning outcomes at the core of Entertainment Design still reflect the need for the student to demonstrate an understanding of the importance of narrative, gameplay and the key principles of interaction design. These concepts are clearly identifiable as central themes that exist throughout the module portfolio, and therefore do not deserve the total focus of the module. Instead, the key skill that we expect the students to develop in this module is to be able to work confidently and creatively in a professional, collaborative, learning environment. From an institutional perspective, it has been recognised that where appropriate, we should encourage such abilities to develop within our students, thus ensuring that our graduates are more prepared for the realities of industry.

For the majority, the module is managed and delivered by two full-time academics - a computer scientist specialising in programming and software design, and a computer artist specialising in visual narrative and interactive game design. For additional expertise out with the main teaching team, colleagues from relevant courses and from within local games companies provide supporting lectures and master classes. The student body for the module consists of three undergraduate cohorts, from BA(Hons) Computer Arts, BA(Hons) Games Design and Production Management, and BSc(Hons) Computing (with Games Development). Collectively, this results in a relatively large class size, which does not reconcile with the teaching model more traditionally suited to the content of such a module.

For each academic session over the last four years, new procedures and opportunities have been introduced. This is partly to capitalise on potential industry or client collaborations and also to ensure that each year the module is fresh. Whilst such changes could be viewed to be unnecessary, feedback from students and external guests remains positive, and the structure of the delivery always remains true to the key aspirations of the module. Nevertheless, the main challenge each year for the teaching team is to manage the expectations of the variety of participating bodies.

As a model for teaching, Entertainment Design fits into accepted classifications for problem-based learning. [1] The module requires students to develop skills in self-directed learning, reflection, and critical analysis within a community of practice where both academic and student are encouraged to share mutual knowledge and interests in a constantly evolving subject area. Savin-Baden discusses the challenges of problem-based learning and presents an overview of the key characteristics of such curricula - 
"1. An acknowledgment of the base of experience of learners.

2. An emphasis on students taking responsibility for their own learning.

3. A crossing of boundaries between disciplines.

4. An intertwining of theory and practice.

5. A focus on the processes of knowledge acquisition rather than the products of such processes.

6. A change in staff role from that of instructor to that of facilitator.

7. A change in focus from staff assessment of outcomes of learning to student self- and peer assessment.

8. A focus on communication and interpersonal skills so that students understand that in order to relate their knowledge, they require skills to communicate with others, skills which go beyond their area of technical expertise." [2]

In general, evidence of these eight attributes can be found within the module structure of Entertainment Design, and to a certain extent, a variety of other modules with the programme portfolio. Throughout the development the module, there has been a natural progression towards problem-based learning strategies. As Boud correctly points out, a key challenge for problem-based learning lies in choosing an appropriate problem "that the learner wishes to solve". [3] In reference to Entertainment Design, most students on the module have a desire to create some form of interactive experience. Therefore at the start of each academic year an important challenge for the teaching team is to define the broad range of potential areas for exploration. This process aims to inspire the students and also ultimately sets the initial tone for the module.

\section{SEMESTER ONE}

Semester one has three main threads:

- Learn Software

- Promote Team Work

○ Encourage Interactive Design

The first thread is to introduce the students to Adobe Flash software and to get them all up to a reasonable standard by the end of the semester. There were a few reasons that Flash was chosen as the platform to be used in this module. Firstly and probably the most important reason is that it has a relatively short learning curve for the student to be able to produce something worthwhile. It is a popular recognized prototyping tool within the industry and many casual games are still produced using this platform [4]. There are many free tutorials available on the internet for students to study at home. All the main browsers have plug-ins which enable Flash pieces to be shown on them. It is not a heavily code based system, so does not put off the nonprogrammers as much as some other platforms but it can be used to produce some very complex programmes if the expertise is available.

For the majority of students their exposure to Flash on their relative courses has been minimal up to this point and the first few weeks of the module are dedicated to bringing all students up to a similar level. It should be noted that there is another small cohort of students who join this module, who may have more experience. These are third year computer science students who have chosen a 'games development' thread to their degree.

The aim is that by week 5 of the semester all students should be at the same level of competence with Flash and can move through the rest of the material together. The semester ends with them producing a simple pong game developing in Actionscript. The thinking behind this thread is that all students should be able to program up to the same standard. This allows any student to be the programmer in the later projects and gives both sets of students an idea of what a programmer has to do as part of a group project. As well as two staff members supporting the students, two students from previous years are employed, as lab assistants, to support the students in their laboratory sessions.

The second thread that runs through the first semester is the emphasis on team working. The students are given lectures on team working and the many pitfalls which can occur when working in groups. The importance of teamwork in a professional environment is stressed as it is the typical method of working for creative companies and that they will be expected to do this when they gain employment. One of the major issues that has been identified for students is that it can often be harder to work in a group at University than in the commercial world. The egalitarian nature of group work at the University is rarely mimicked in the commercial sector, where typically a defined hierarchy is clearly established through roles and pay structures. In a University environment the focus is different and as there is no ranking system among the students (and it is difficult to enforce one) there is often no boss to take decisions or shoulder the responsibility should things not go as planned. Therefore students are taught not only that problems will arise but that they have to be managed effectively by the group.

The third and vitally important thread is the lecture series on interactive design, which covers topics such as visual style, narrative, and emergent media. These are supplemented by external speakers from various areas of the interactive industry e.g. BBC Scotland and Denki games. The talks are used to reinforce the design lectures and also to demonstrate how there is no standard 'correct' method of designing an interactive piece.

In the lecture series the roles in a team for producing an interactive piece are discussed and again this is backed up by the external lectures. This gives the students an idea of the various tasks and roles required to complete a project and particularly what other people do within a team other than what they specialize in themselves. Understanding the roles and an appreciation of the flexibility required in producing a piece of interactive entertainment all leads into the second semester where the students will be undertaking roles within a group producing an interactive piece.

The assessment for semester one comprises sixty per cent of the whole double module and is split equally between an interactive concept design and an interactive Flash piece. Assessment covers various areas but is mainly focused upon the amount of research and development that has been put into the characters and the design as well as the amount of work and thought put into the simple game implementation. 


\section{SECOND SEMESTER}

At the start of semester two the students are placed into groups of six or seven. Although various selection methods have been tried this is currently done by placing the students with the best marks for the implementation part of assessment one into groups in a round robin convention. The students are allocated this way until all are placed into groups and aims to ensure teams of equally skilled programmers. They are also handed out project briefs which state what is required of their group in the semester but also has ideas that external companies have suggested and have an interest in seeing pursued. These can be one off ideas that are specific and quite detailed or can be general areas of interest of companies. If a group selects a specific company project then they will have a company mentor attached to their group and they will be invited to join the academics in the progress meetings throughout the semester.

At the first meeting each student is handed a contract. This is an individual contract and has to be filled in by the student stating what they are going to do and deliver for the project. The idea behind this is to get the students thinking about what roles they will fulfill and how those roles break down into artifacts. It also gives them something to assess their progress with during the project. The students usually have a couple of drafts at the contract before it is signed off. The initial group meeting is also used to remind students of the tools that are available to them to assist them in their work e.g. blogs, wikis, messenger services, email, WebCT, skype phones [5]. Also at this initial group meeting the students are asked to think about the roles within the group they would like to fulfill and the concepts for their interactive piece [6]. Very rarely do groups have ideas at this initial meeting, so they are asked to come back with one or two concepts for the next meeting and a proposal for individuals roles within the team.

The second semester has some external speakers discussing the implementation of projects and the issues to be aware of. The laboratory sessions are spent with the students working in their groups on their projects with support from previous cohort students. During the laboratory sessions, each group is reviewed by staff to check on progress and to see if any problems have occurred that are causing concern. [7, 8].

The emphasis is on flexibility and encourages students to reexamine existing designs as well as for them to reflect on what they have learned in semester one. They are reminded that each of them has come up with a concept in semester one and they can utilize any one of these concepts or a combination of ideas or start from scratch. Characters that they developed in semester one can also be used in their group project if desired.

In terms of team working students can assign roles however they wish. In theory, artists could do programming, coders could design and create art assets etc. It is entirely down to the group to decide who does what. They may also 'outsource' work to other students and friends if they wish, as long as the module staff are made aware of this, they don't declare the work as their own and that each students' contract has enough content for them to be fairly contributing to the group effort.

Once the groups are underway, have signed contracts and established an agreeable concept, the management of expectations becomes important. If students have chosen a project brief from a company the module staff may have to manage three different levels of expectations at this point.

The first is from the students themselves who tend to be overly optimistic with what they think is feasible within a semester and usually underestimate the amount of time available but overestimate the skills and abilities of the team as a whole. This has to be managed carefully in order not to diminish the student's enthusiasm while ensuring that their expectations can be realised within the modules timeframe. Input from both the academic and industry professionals in the form of anecdotal discourse and reference to more formal project management methodologies ensure that the students can proceed with confidence. The scaling back of the original idea into a more achievable and focused interactive prototype is an iterative process that occurs over the semester.

The second level of expectations to be managed are those of external companies, who may have forgotten what it was like to be a second year undergraduate student and who are expecting the quality and quantity of work to be comparable to their own staff. These expectations are difficult to manage because they are initially similar to the students' expectations. It is the responsibility of the academic staff to negotiate a realistic outcome that meets the required level of quality.

Lastly there are the academic staff's own expectations that need to be managed. In theory these should be the easiest to attain but in practice they are difficult to harmonise with the other levels of expectation. The main thinking behind the staff's expectations are that the students enjoy the creative process and create a piece of interactive entertainment that is capable of being presented. For the staff it is important that by enjoying the process the students can build upon the experience in subsequent modules and continue to develop skills in the following areas:
○ Programming Awareness
○ Principals of Interactive Design
- Collaborative Working Techniques
- Communication and Critique of Concepts
○ Project Management Skills
- Professional Approaches to Problem Solving

The module immediately takes students out of their comfort zone and staff are frequently required to support and provide additional mentoring out with the normal timetabled schedule. There are times where the staff have to intervene and 'referee'. There are a variety of issues that arise however some common problems can be identified.

One of the most common problems is with group members who are not considered to be pulling their weight according to the other team members. This can be the case of a student who has not engaged and does not want to engage. In these cases the staff and students typically discuss the specific issues and are usually resolved to everyone's satisfaction. In the rare cases where agreement is not forthcoming or able to be negotiated individuals can be referred to their academic tutor and can be set individual assignments. Whilst this is not ideal the students are encouraged to reflect upon group working and its benefits. The student still attends the lectures and discussions about group work and design but they miss out on the practical process. Consequently their 
reflective report is important to ensure that they have understood what is required from group working.

Lack of self-confidence or too much confidence is another common problem. Students who are too shy or generally lack the confidence to express themselves effectively to their peers requires careful management. Staff have to identify the specific problems and subsequently build up their confidence up in order for them to communicate openly. The use of alternative methods of communication such as wikis or bulletin boards are often beneficial in these cases as people feel more confident writing than in face to face discourse. Conversely forceful personalities and fragile egos can be as difficult to manage. Usually these manifest themselves in students who are highly ambitious and want to do well. Explaining to them that a large part of the module is about working in teams, usually helps to convince these students of the need to include the rest of their group in the decision making processes.

The pressure of expectations themselves is another source of anxiety. Some students do want to engage but are daunted by the task ahead or the assumed expectations of their peers, the staff and/or external companies and because of this they become detached from the group. Again, staff undertake the role of counsellor and meet students one to one to discuss the problems. Generally giving students the necessary assurance that other people feel the same and in emphasising that they have the required skills to successfully contribute to the group effort.

Unfortunately, life and other coursework deadlines interfere with the smooth running of this module. Groups are encouraged to plan for contingency or to prioritise the required features accordingly. Where doubt remains within individuals or the team as to the overall value of the group work staff undertake frequent reviews and positive reinforcement techniques to ensure that the focus remains on learning in a fun environment.

The assessment for semester two comprises forty per cent of the whole double module and is split into three parts. The first part is the prototype itself which is worth twenty percent of the marks. The second part, worth ten percent, is a presentation by the whole group to 'pitch' their prototype to the staff and company representatives. The final part is an individual reflective report on the students role in the group, where they can review what went well or what went badly and how they would improve upon this in future. By careful progress checking throughout the semester the staff are aware of who is doing what in each group and present marks for the prototype and the presentation with this in mind. The individual reflective report is used as confirmation to the staff as to how they understood the group performed and to find out those little 'things' that did not come up in meetings. As well as checking whether the student fully understood the purpose of the module and if they had learned from any mistakes. [9]

From a staff point of view the key results are that the students had fun during the project and developed confidence in group working. The fact that many of the students are keen to carry on in the summer holidays, and beyond, working either to enhance their own portfolio or specifically with companies on more advanced projects for little recompense, indicates that these main objectives have been mostly fulfilled.

\section{PROTOTYPE}

One of the projects that enabled students to apply the experiences and skills learned from the Entertainment Design module into a practical industry-focused environment was Prototype. The project encourages closer academic and industry collaboration and aims to enhance student skills for the creative industries. [10,11]

Prototype was intended as a hothouse, innovation studio, bringing together University of Abertay Dundee, BBC Scotland and commercial games developers and start-ups in Tayside and beyond, to design and develop new interactive products, technologies and games aimed primarily at engaging with future audiences and online communities. The project created a forum to support innovation through shared knowledge and information about new opportunities, technologies and techniques and disseminated best practice models for publishing new forms of interactive content.

The primary benefits of the project for the University and the $\mathrm{BBC}$ have been in establishing a positive and collaborative relationship and in broadening the creative and technical scope of projects undertaken. All participants have gained from the knowledge sharing. One example of this has been the update to the State of Play research that the BBC conducted into gamers behaviours in 2005. [12] This research helped focus projects on specific areas for development and in considering the growing importance of multiplayer and social networking elements in the projects. The creation of a folio of creative and technical research together with the development of a working prototype was mutually beneficial and also gave the students relevant industry experience that will stand them in good stead for their future careers.

Running from $1^{\text {st }}$ April 2008 until the $31^{\text {st }}$ March 2009 the project brought together production design and development staff from BBC Scotland's New Media and Future Media \& Technology departments, with students from Abertay University studying Computer Arts, Computing Games Development and Games Production Management. The teams comprised of students from many different courses and divisions but all were part of the School of Computing and Creative Technologies. While the project was open to students from all years the majority of student participants were from $3^{\text {rd }}$ year, as this was mutually beneficial. The students could satisfy academic requirements for their personal and group modules, through participation in the project and for Prototype we had students who had participated in the Entertainment Design module and could build upon this experience. In total there were 8 student teams that worked on multiple concepts and projects throughout the year. Each team had students who had successfully completed the Entertainment Design module and were now able to apply the learning outcomes in a practical setting with a commercial client.

The project work was undertaken in development blocks across three phases. The initial plan was to have several teams, made up of students from different courses rapidly prototype ideas and concepts provided by the $\mathrm{BBC}$, with the aim of delivering a working prototype by the end of the semester. This worked well in the first phase of the project but had to be modified in the second phase to ensure that all students could still meet all their academic commitments. As a result the project had some teams work on projects across two semesters in order to fit in with their academic calendar, while others were able to continue down the rapid prototyping route. The project was fortunate to have both 
the support of Academics and an experienced and flexible client in the BBC to allow changes to the project structure as required. In total the students were expected to contribute approx. 10 hours a week as part of their academic schedule in order to design and develop ideas from initial one-line briefs. In practice several teams and individuals contributed far more than this whilst still maintaining their other academic and work-life commitments. The value of rapid prototyping is well known and is widely practiced throughout the games industry, the challenge for the project was to adapt that to an academic context where few of the participants had any previous experience. [13]

The students participated in initial brainstorming sessions held at both UAD and BBC Scotland at the start of each phase. On these days the students worked collaboratively with both BBC staff, UAD Academic Staff and interested staff from games and digital media companies. The original briefs were provided by BBC and the initial ideas that came out of the brainstorming sessions would be further developed and refined over a further couple of weeks, throughout which the students would receive feedback from the $\mathrm{BBC}$ on the concepts. These ideas were then refined and documented in various forms. Students generally used wikis for collaborative working but were also required for both the client and academic purposes to provide standard documents such as a Design Document and Project Plan. After the basic designs were documented the teams worked collaboratively to produce the project working on an iterative design and development basis. [14]

The student teams were self-organizing and generally benefited from following more agile project methodologies, dividing up the broad tasks based on their degree course and background. [15] Computer Arts students would develop concept artwork and move onto all art assets, Games Production Management took a dual design and project management role with Creative Sound Production students focused on audio design and assets. The teams were also joined by student programmers from the Computing (Games Development) course, specialised industry professionals brought in on part-time contracts and BBC staff. Over the next few weeks the students worked collaboratively with the BBC staff and industry professionals to develop working prototypes and it was within this period that the teams experienced as far as possible the issues in designing and developing in a commercial environment whilst managing the expectations of all the participants and stakeholders.

Managing the expectations of the students, academics, the principal client $(\mathrm{BBC})$ plus other third-parties brings with it a range of challenges. In particular there were three significant issues:

\section{- Participants Expectations \\ - Intellectual Property (IP) Arrangements and Small- Medium Enterprise (SME) Engagement \\ - Academic Considerations}

As previously cited it is generally the students' expectations that are the highest at the outset. Students feel confident that in working with both the client and other industry professionals they can fully achieve the grand plans that they discussed and developed in the initial brainstorming sessions and refined in the first few weeks of the project. For the client it is difficult to accurately gauge the expectations. On the one hand it is easier to clearly define what they expect - in the case of Prototype for each project the teams were expected to deliver on a clear concept, detailed design and working prototype. While the working prototype aimed to deliver only about ten percent of the full design, all parties encounter the problem that to provide a vertical slice of the full application often requires significantly more than ten percent of the functionality to be developed. The client therefore encounters the same issues that many companies face internally in prototyping ideas. First of all the students are not full-time dedicated resources and have other duties and responsibilities to manage. Secondly although the teams work collaboratively they are not managed by the client on a full-time basis and it is possible for the teams to deviate from agreed features and plans if they don't have regular contact with the client.

Academics expectations are more realistic, and this is reflected in the academic focus of the project in that goals are more related to achieving learning outcomes and for the students to get the most of the experience, and not necessarily tied to the production of a working prototype. While there are clear and understandable academic considerations for such an approach it is often in contrast to that preferred by the client or industry as a whole, where pitching an idea successfully is often contingent on being able to demonstrate it through a working prototype. The final groups to consider are industry professionals, who are without doubt the most realistic, but that realism has to be tempered so as not to border on cynicism. Each student and each team is a relatively unknown quality and good teams can gel quickly and with the right support can genuinely deliver new ideas and creativity and demonstrate this with a working prototype. However the immediate reaction is that the briefs are difficult to achieve due to the issues of time, resources and money, an attitude generally born from experience.

Expectations are also challenged by the practical realities of project development. An early issue in the Prototype project was that funding was tied to the successful conclusion of an IP Agreement between the client and the University. Initial progress stalled and the agreement took significantly longer to progress than any party originally anticipated. In the meantime the lack of an agreement made it more complicated for the actual participants to understand the potential ownership of ideas and for SMEs to become involved. For both groups there was an underlying concern than the client could potentially own the project output. For students it is often the lack of experience in the commercial world that makes them wary of putting their best ideas forward. Everyone believing that they have the killer application or game that will make them rich and successful. The harsh reality is that when they graduate and begin working for a company that they also will have to potentially sign over the rights to their ideas as part of their employment contract.

For many of the SMEs the expectation was very much that if they were involved in a project with the BBC where new IP was developed then they should have the right to share in its success. The BBC, on the other hand, had to deal with the complexities of their own background IP and how to protect it in a shared collaborative project. All in all the issues were resolvable but it required much more negotiation and legal involvement than had been anticipated. Again it was necessary for all parties to be flexible and the experience of both the BBC and the University of Abertay Dundee in understanding these challenges helped to bring about the successful conclusion of the agreement. 
Another significant challenge was dealing with the multiple academic requirements and considerations from a wide range of courses and students from different divisions. Simple issues of timetabling became incredibly difficult for the students and for the client. Students had to contend with arranging a few meetings onsite in White Space but the bulk of the work being conducted elsewhere, at their own arrangement. The client had to contend with arranging days purely to attend meetings and not necessarily to undertake the collaborative role that was initially envisioned. Whilst a simple issue like timetabling was an inconvenience working with multiple courses and divisions towards academic credit was incredibly challenging. Balancing client and project requirements with academic output required flexibility in many of the academic processes and it was clear that some divisions were more experienced and far better equipped at dealing with this than others. Despite many discussions unfortunately there wasn't a simple solution that could be applied across the board and issues arose as students looked to focus on academic requirements above those of the project and client.

Whilst there were major challenges that had to be dealt with and as with many real-world projects the solutions were often the result of necessity and compromise. The project has nevertheless been successful in the majority of its aims and as with any pilot the expectations should be easier to predict and manage in future. In particular the overall process of prototyping ideas in an environment where each participant could make a valuable contribution was incredibly beneficial. It is difficult to single out any one project or team for specific praise, as the scope of the projects differed widely and each team had their own challenges to overcome. Briefs were undertaken from various departments in the $\mathrm{BBC}$ and solutions ranged from content-heavy prototypes to more technical demonstrations, and we learned from each project how to shape the process a little bit further. The key element that made the project successful was the flexibility of all participants. From the client side the ability to divert resources to support projects when required, through to the students willing to develop new skills to help create a prototype and the academics to look at the overall experience as a valuable learning outcome everybody had to be flexible in their approach and in their expectations. From the academic perspective collaborative projects need to be flexible enough to take on board the differing priorities of the client. Typical academic emphasis on process above product and mentoring over critique are diametrically opposed to a clients need to demonstrate that any investment of time and money is worthwhile from a commercial perspective. For Prototype one of the real benefits of working with a client as experienced as the $\mathrm{BBC}$ was the focus that client brought to establishing clear briefs and deliverables and how they worked collaboratively to achieving prototypes that could be shared and played.

\section{CONCLUSION}

In a constantly changing field of knowledge, the relative success of the Entertainment Design module is due to the key aspirations and processes that underpin the form of its delivery and management. Flexibility is core - whether this relates to choosing appropriate moments to conduct mentoring, providing opportunities for external clients to become involved, or allowing the students to undertake a completely alternative approach to solving the problem of the brief.

The module is a constant balancing act of expectations between the students, staff and external companies. This is very similar to the compromises that occur in games and other creative companies every day where staff, management and publishers aims are hopefully fulfilled without sacrificing quality of product.

As previously discussed, problem-based learning only works when students are tasked with solving a problem that genuinely interests them. In this instance the role of the mentor is to instil a sense of ownership of the project, whereby students feel comfortable taking control. Entertainment Design, Prototype, and the collaborative learning environment of White Space, all facilitate learning through a culture of play, creation, innovation and collaboration.

Through experience it has become clear that utilising established methodologies in collaborative learning and team work will not suit all students. Nevertheless this can be managed by presenting individuals with the opportunity to define their own learning goals, deliverables and milestones, which will provide a similarly rewarding pathway through the module.

Staff and student interaction should focus on communicating the importance of process as opposed to product, and through supportive mentoring, students can confidently explore their ideas without fearing a harsh, creativity destroying critique.

These aspirations ensure that students become more confident learners and are therefore better equipped to engage with external companies, and excel within intensive development projects such as Prototype.

\section{ACKNOWLEDGMENTS}

Our thanks to the students and staff of the School of Computing and Creative Technologies, University of Abertay Dundee, the staff of New Media and Future Media and Technology at BBC Scotland, Scottish Enterprise, Electric Top Hat, Realtime Worlds, Mark Grindle Associates, Wangbar and Denki

\section{REFERENCES}

[1] Margetson, D. 1991. Why is Problem-based Learning a Challenge? In Boud, D. and Feletti, G. Eds. The Challenge of Problem-Based Learning. Kogan Page, London 45-46.

[2] Savin-Baden, M. 2000. Problem-based Learning in Higher Education: Untold Stories. Open University Press, Buckingham, 17-18.

[3] Boud, D. 1985. Problem-based learning in perspective. In Boud, D. Ed. Problem-Based Learning in Education for the Professions. Higher Education Research and Development Society of Australasia, Sydney, 13.

[4] Andrzejewski, A. 2008, Quick and Easy Flash Prototypes Bring Your Wireframes to Life, http://www.boxesandarrows.com/view/quick-and-easy-flash

[5] Lister, M. Dovey, J. Giddings, S. Grant, I. and Kelly, K. 2009. New Media - A Critical Introduction ( $2^{\text {nd }}$ Edition $)$. Routledge

[6] Belbin, R. M. 1993. Team roles at work. ButterworthHeinemann, Boston.

[7] Drury, H., Kay, J. and Losberg, W. 2005 Building community: Perceptions of group work over a three-year undergraduate degree program in computer science. HERDSA (Higher Education Research and Development Association of Australasia) conference: Higher Education in a changing World, 3-6 July 2005. University of Sydney. 
[8] Toseland; R. W. and Rivas, R. F. 1984. An Introduction to group work practice. Collier Macmillan, London

[9] Winchester-Seeto, T. (April, 2002). Assessment of collaborative work - collaboration versus assessment. Invited paper presented at the Annual Uniserve Science Symposium, The University of Sydney, 5th April.

[10] Leitch, S. 2006 Prosperity for all in the global economy world class skills, HM Treasury; HMSO.

[11] Skillset. 2008. Sector Skills Agreement for the Creative Media Industries (Scotland). Skillset.

[12] Pratchett, R. 2005. Gamers in the UK: Digital play, digital lifestyles.
http://open.bbc.co.uk/newmediaresearch/files/BBC UK Ga mes Research 2005.pdf

[13] Carter, T. 2009. Opinion: How We Can Reshape The Game Industry, Gamasutra, http://www.gamasutra.com/phpbin/news index.php?story $=22045$

[14] Gabler, K. Gray, K. Kucic M. and Shodhan, S. 2005. How to Prototype a Game in Under 7 days, Gamasutra, http://www.gamasutra.com/features/20051026/gabler_01.sht $\underline{\mathrm{ml}}$

[15] Schwaber, K and Beedle, M. 2002. Agile Software Development with Scrum, Prentice Hall, Upper Saddle River, NJ: 107-108 